\title{
The 3D Numerical Study of Flow Regimes within Bubble Column Reactor
}

\author{
Mojataba Goraki Fard, Youssef Stiriba, Xavier F. Grau \\ Universitat Rovira i Virgili, Departament d'Enginyeria Mecanica \\ Av. Paisos Catalans 26, 43007 Tarragona, Spain \\ mojtabagoraki.fard@urv.cat; youssef.stiriba@urv.cat; francescxavier.grau@urv.cat
}

\section{Extended Abstract}

The majority of industries engaged in two-phase flow (air-water) or multiphase flow (air-water-solid) materials are trying to meet maximum possible achievements such as high quality of mixing and maximum rate of heat transfer, with spending the less amount of investments. Bubble column reactor (BCR), probably, is a suitable solution to the industrial aims owing to providing lots of benefits such as: effective rate of mixing, high rate of interfacial area, high heat and mass transfer rate, low rate of maintenance requirement, ease of operation and low rate of operation costs (due to the lack of moving parts).These days, there are lots of interest to use BCR in various kinds of industries such as: chemical gas cleaning, various bio technological application, and chlorination, alkylation and polymerization industries. However, the lack of understanding of flow physics such as hydrodynamic behaviour (owing to existence of coalesce and break up phenomena within reactor in high value of superficial gas velocities) as well as the complexity to evaluate the mass and heat transfer within the reactor, not only the prediction of flow behaviour but also the scale up of the BCR become very hard to achieve $[1,2,3,4,5,6]$.

In this work, the two phase flow within multi-phase BCR is modelled through the Euler-Euler (E-E) approach. Accordingly, both phases such as dispersed and continuous phases are introduced in Eulerian framework, that is, they are treated as a continuum which interpenetrate with each other. In E-E approach, understanding the individual movements of the dispersed (bubbles) in liquid is not essential to focus on (considering overall motion is enough) and bubble properties are obtained through a set of interfacial momentum transfer terms included in conditional averaged Navier-Stokes equations (such as drag, virtual mass, lift and turbulent dispersion) [7]. To examine the chaotic behaviour of two phase flow within reactor, we use RANS turbulent models (to be exact: $k-\epsilon$ and Mixture k- $\epsilon$ ). Moreover, the computational domain is created in Gmsh software and, the numerical simulation is carried out through the Open-FOAM (Field Operation and Manipulation) software package or specifically twoPhaseEulerFoam solver [8, 9].

This CFD work proposes the 3D finite volume (FV) computational domain to study and estimate different flow pattern (homogenous, transient and heterogeneous flow regimes) within BCR. The two phase system consists of air-water at room temperature $\left(24^{\circ} \mathrm{c}\right)$. The reactor diameter, the height of the column and the initial level of the water are $0.1,2,1.35 \mathrm{~m}$ respectively. The averaged bubble diameter is considered as a fixed value of $4 \mathrm{~mm}$. Besides, flow structure within bubble column reactor for different ranges of superficial gas velocities $(1.35$ to $8.4 \mathrm{~cm} / \mathrm{s})$, are analysed and compared with experiments. Besides, the lift force did not improve our results, then, we deduced that considering the drag, virtual mass and turbulent dispersion forces were enough to express dominant flow behaviour (specifically at the centre due to existence of big bubbles) inside the reactor.

\section{References}

[1] Ch. Vial and Y. Stiriba, Characterization of Bioreactors Using Computational Fluid Dynamics. CRC Press Taylor and Francis Group, pp. 121-164, 2013.

[2] R. Krishna, M. I. Urseanu, J. M. van Baten, J. Ellenberger, "Influence of scale on the hydrodynamics of bubble columns operating in the churn-turbulent regime: experiments vs. Eulerian simulations," Chemical Engineering Science, vol. 54, no. 21, pp. 4903-4911, 1999.

[3] Vivek V. Buwa and Vivek V. Ranade, "Dynamics of gas-liquid flow in a rectangular bubble column: experiments and single/muli-group CFD simulation,” Chemical Engineering Science, vol. 57, pp. 4715-4736, 2002.

[4] T. Ziegenhein, R. Rzehak, D. Lucas, "Transient simulation for large scale flow in bubble columns," Chemical Engineering Science, vol. 122, pp. 1-13, 2015. 
[5] D. Zhang, N. G. Deen, J. A. M. Kuipers, "Numerical simulation of the dynamic flow behavior in a bubble column: A study of closures for turbulence and interface forces," Chemical Engineering Science, vol. 61, no. 23, pp. 7593-7608.

[6] R. M. A. Masood, A. Delgado, "Numerical investigation of the interphase forces and turbulence closure in 3D square bubble columns," Chemical Engineering Science, vol. 108, pp. 154-168, 2014.

[7] Gerhard Holzinger, Austria (January 2018), OpenFOAM A Little User-Manual.

[8] OpenFOAM Ltd., United Kingdom (2015), OpenFOAM-3.0.1 user's guide.

[9] A. Behzadi, R. I. Issa, H. Rusche, "Modelling of dispersed bubble and droplet flow at high phase fractions," Chemical Engineering Science, vol. 59, pp. 759-770, 2004. 